\title{
Primary epithelioid haemangioendothelioma of the liver: case report and review of the literature
}

\author{
Rupesh K Pokharna, Pramod Kumar Garg, Siddhartha Datta Gupta, Usha Dutta, \\ Rakesh K Tandon
}

\begin{abstract}
A 31 year old female patient presented with a one and a half year history of pain in the upper abdomen. The pain was mild, constant, dull aching, and increased with change in posture or sudden movements. There was no definite relation to meals. She also had a lump in the right upper quadrant, which had been gradually increasing in size over three months. She had mild anorexia and reported a $5 \mathrm{~kg}$ weight loss over one year. She had no history of intake of oral contraceptive drugs, exposure to vinyl chloride, thorotrast or any other industrial toxin. Ultrasonography of the abdomen revealed multiple space occupying lesions of altered echotexture in both lobes of the liver. The portal venous system and hepatic vascular system were normal. Computed tomography of the abdomen confirmed the ultrasound findings. Histopathology was diagnostic for primary epithelioid haemangioendothelioma; the first such case reported from India. The patient has been put on a waiting list for a liver transplant. ( Clin Pathol 1997;50:1029-1031)
\end{abstract}

Keywords: primary epithelioid haemangioendothelioma; liver malignancy

Primary malignant tumours of the liver other than hepatocellular carcinoma are mainly sarcomas; however, sarcomas arising primarily in the liver are quite uncommon. The most common sarcoma is angiosarcoma, others being leiomyosarcoma, fibrosarcoma, and liposarcoma. ${ }^{1}$ A rare variety of angiosarcoma arising from the liver is epithelioid haemangioendothelioma. ${ }^{2-8}$

We report a case of primary epithelioid haemangioendothelioma of the liver along with a review of the literature. To the best of our knowledge, this is the first such case reported from India.

\section{Case report}

A 31 year old female patient presented in June 1995 with a history of pain in the upper abdomen for one and a half years. The pain was mild, constant, dull aching, and increased with change in posture or sudden movements. There was no definite relation to meals. In addition, she noticed a lump in the right upper quadrant of her abdomen three months before presenting to our hospital. The lump was gradually increasing in size. She also had mild anorexia and reported a $5 \mathrm{~kg}$ weight loss over a period of one year. She denied any history of dyspepsia, fever, jaundice, gastrointestinal bleeding or oedema over feet. She had had three normal deliveries and a normal menstrual history. There was no history of intake of oral contraceptive drugs, exposure to vinyl chloride, thorotrast or any other industrial toxin. She was a non-smoker and did not consume alcohol. Physical examination revealed a woman with thin build (weight $52 \mathrm{~kg}$, height $158 \mathrm{~cm}$ ). There was no pallor, jaundice, clubbing, pedal oedema, spider naevi or any significant lymphadenopathy. Systemic examination of the central nervous system, cardiovascular system, and respiratory system was unremarkable. Abdominal examination revealed a hepatomegaly of $8 \mathrm{~cm}$ below the right costal margin. The liver was non-tender, its consistency was firm and surface grossly nodular. There were no prominent veins over the abdomen, free fluid, splenomegaly or any bruit. A probable clinical diagnosis of neoplastic lesion of the liver was entertained.

Routine haematological and biochemical investigations were normal. Liver function tests showed normal bilirubin $(0.2 \mathrm{mg} / \mathrm{dl})$, normal aspartate and alanine transaminases (24 and $18 \mathrm{IU}$, respectively), and mildly raised alkaline phosphatase (420 IU; normal 20-200). Viral markers for hepatitis $B$ and $C$ viruses were negative (HbsAg, anti-HbcAg and anti-HCV antibodies; ELISA, Abbott Laboratories, Chicago, Illinois, USA). Serum $\alpha$ fetoprotein level was well within the normal range $(2.4 \mathrm{ng} /$ $\mathrm{ml}$ ). Ultrasonography of the abdomen revealed multiple space occupying lesions of altered echotexture in both lobes of the liver. The portal venous system and hepatic vascular system were normal. Computed tomography (CT) of the abdomen confirmed the ultrasound findings (fig 1). A Tc99 RBC pooled scan showed multiple cold regions in the liver not suggestive of haemangioma. A Tc99 phytate liver scan showed an enlarged liver with good radiotracer contrast, multiple photopenic areas in the right lobe but uniform tracer distribution in the left lobe.

For histopathological diagnosis, a Trucut liver biopsy was done from the largest lesion in the right lobe of liver under ultrasound guidance. Histological examination of the liver biopsy revealed replacement of the liver parenchyma by cells enmeshed in an eosinophilic to faintly basophilic matrix. At places, only isolated or groups of hepatocytes could be identified. The hyalinised areas showed variable 


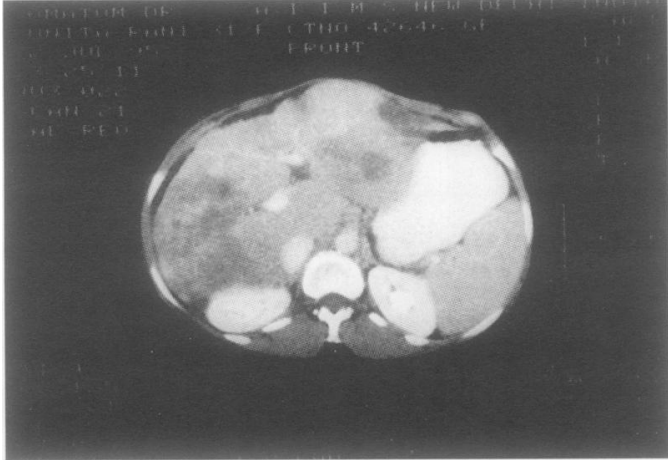

Figure 1 CT showing a large multinodular tumour involving both lobes of the liver.

cellularity. The cells predominantly had indistinct cytoplasm. When discernible, these cells were either rounded or spindle shaped. Nuclei were oval to spindle shaped with finely granular chromatin. Many of these cells showed cytoplasmic vacuolation giving a signet ring-like appearance (fig 2). Portal tracts were expanded due to fibrosis and infiltration by the tumour. There was bile duct proliferation. Reticulin

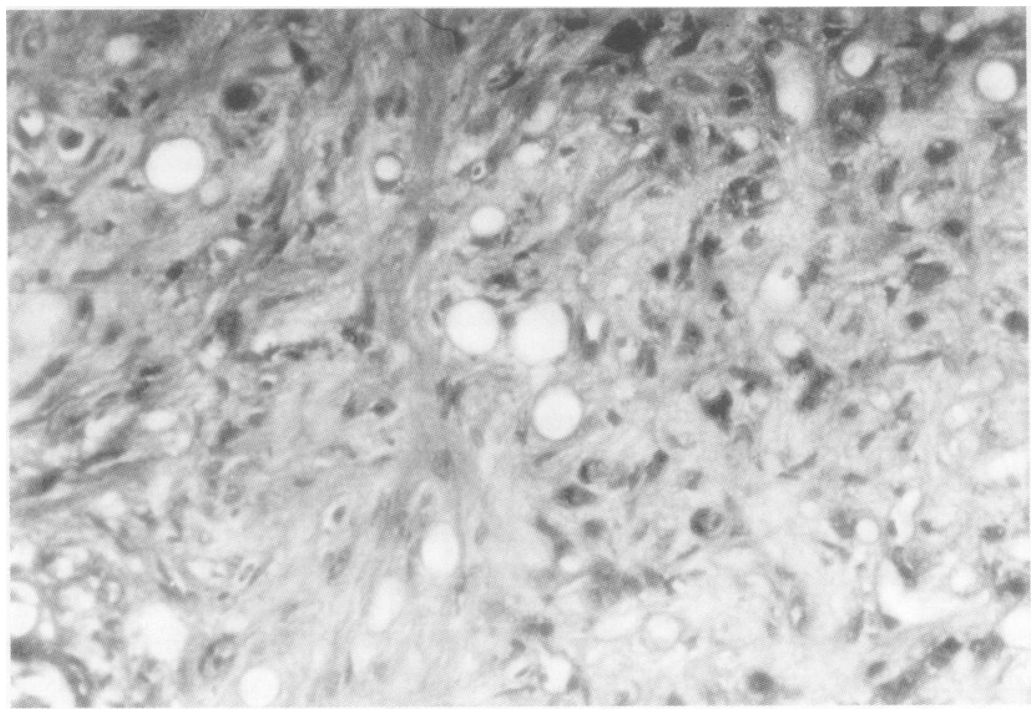

Figure 2 Liver biopsy showing replacement of liver parenchyma with tumour cells many of which are spindle shaped or show cytoplasmic vacuolation (haematoxylin and eosin, original magnification $\times 20$.)

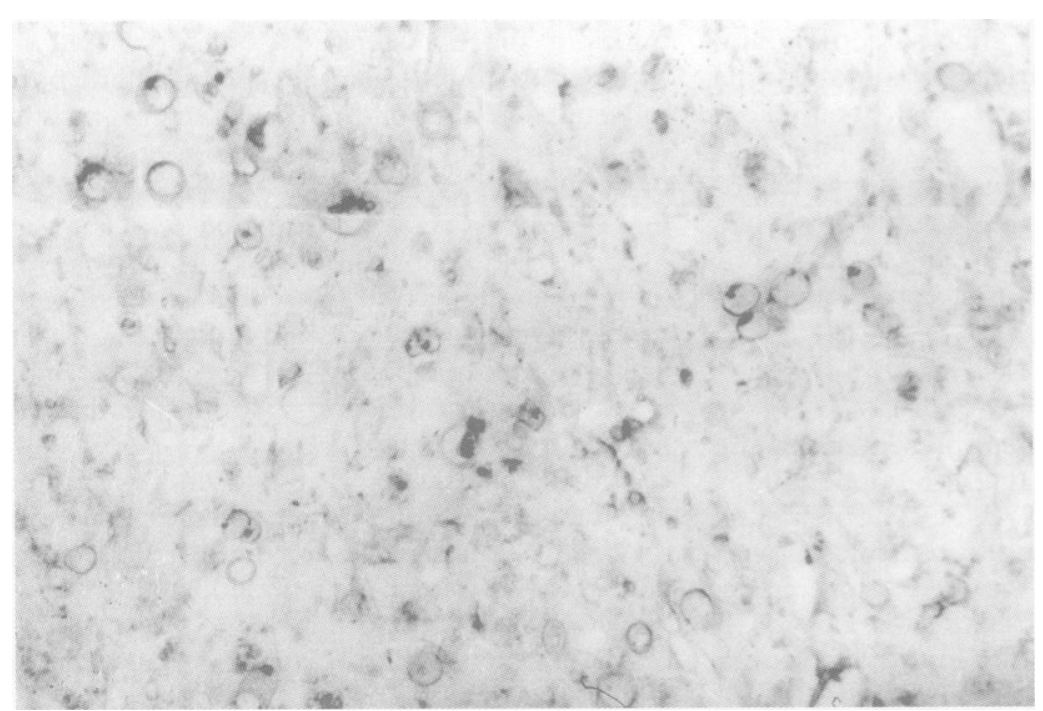

Figure 3 Factor VIII immunostaining highlighting the vacuolated cells (factor VIII antigen $\times 10$.) stain and Mason trichrome stain highlighted the fibrosis. In addition, numerous vascular channels were identified on reticulin staining. The tumour cells did not contain mucin (Mucicarmine stain). Immunohistochemical staining showed factor VIII (Dakopatts, Glostrup, Denmark) positivity in some of the vacuolated tumour cells (fig 3). Staining for Ulex europaeus lectin (Dakopatts) was equivocal. The immunohistochemical stain for cytokeratin (Dakopatts) highlighted the intervening hepatocytes but the tumour cells were negative. These histological features were consistent with an epithelioid haemangioendothelioma.

\section{Discussion}

Solid angiosarcomas of the liver are rare tumours and epithelioid haemangioendothelioma is one of the rarest of the sarcomas arising from the liver. This particular tumour has been given many names: vasoablative endotheliosarcoma with pseudocartilagenous change, mixed tumour, sclerosing endothelioid angiosarcoma, pseudocartilagenous sarcoma, and sclerosing interstitial vascular sarcoma. Many case reports have been published describing clinical, radiological, and histopathological features of this tumour. ${ }^{2-8}$ The largest series remains that by Ishak et al. ${ }^{3}$ Apart from the liver, epithelioid haemangioendothelioma may arise from many other organs such as bone, lungs, muscle, and blood vessels. ${ }^{9}$

The clinical behaviour of epithelioid haemangioendothelioma is that of a slow growing malignant tumour with relatively long survival. ${ }^{310}$ Most patients have non-specific symptoms and in many patients the tumour is diagnosed serendipitously. The common symptoms are upper abdominal pain, anorexia, and weight loss. The less common are jaundice, fever, and variceal bleed secondary to portal hypertension (which is rare). A fulminant course has also been described." The whole liver is ultimately replaced by the tumour. Metastases to bone, pleura, and lymph nodes have been described.

Radiological investigations such as ultrasound and CT are helpful in defining the extent of the tumour. ${ }^{12} 13$ Recently, magnetic resonance imaging of epithelioid haemangioendothelioma in the liver have been described. ${ }^{14}$ The CT findings in our patient matched those reported in the literature. The CT findings compatible with a diagnosis of epithelioid haemangioendothelioma are a large tumour with peripheral enhancement, many hypervascular central lesions, compensatory hypertrophy of the unaffected areas, and nodular appearance. A nuclear scan may be helpful in excluding a vascular tumour such as haemangioma as was the case in our patient. ${ }^{15}$ Despite an endothelial origin this tumour is relatively avascular. Angiography is not of any particular help and angiographic findings have been variously described ${ }^{5}{ }^{10}$ : these include moderate vascularisation, curving displacement of marginal vessels, and peripheral enhancement of the tumour by contrast.

The histopathological features of this tumour described are characteristic. ${ }^{316}$ 
Microscopically, the tumour comprises neoplastic cells that are round or spindle shaped with large nuclei. At the margin of the tumour, large plump cells fill the sinusoids while the centre of the tumour has a fibrous stroma. The stroma of the tumour tissue adds the distinctive feature; it is fibrous, strongly resembles cartilage, and is basophilic. It is because of its resemblance to the cartilage that the name pseudocartilagenous sarcoma was given to this tumour. The tumour characteristically stains positive for factor VIII related antigen, ${ }^{3-11}$ Ulex europaeus I lectin, ${ }^{17}$ and Q-bend 10 (CD34) antigen. ${ }^{18}$ The liver tissue gets slowly replaced by fibrous hyalinised tissue. The endothelial nature of the tumour can be shown by demonstrating intracytoplasmic inclusions similar to Weibel Palade bodies. ${ }^{19}$ The large number of intermediate filaments gives the tumour cells their epithelioid appearance. The histological features of this tumour were well illustrated in our patient.

The biological behaviour of this tumour on which depends the clinical course should be understood in light of its histopathological characteristics. Since it is a slow growing tumour, there is a long survival. The tumour rarely infiltrates the vessels and lymphatics and hence has low propensity to metastasise. The tumour is relatively avascular, mainly fibrous and solid, and so there is little chance of rupture. In fact there is a tendency for "self death" because when the tumour enlarges and becomes surrounded by dense fibrous tissue, it cuts off its own blood supply. ${ }^{20}$

The aetiology of this tumour is not known. Association with oral contraceptives and vinyl chloride has been reported. ${ }^{41121}$ In our case no definite predisposing factor could be identified.

The tumour is generally not amenable to surgical resection owing to its multinodularity/ multicentric origin involving both lobes of the liver. Surgical resection has been described in a few patients. ${ }^{10}$ Nor is the tumour responsive to radiotherapy or chemotherapy although an occasional patient may respond to intraarterial 5-FU through the hepatic artery. ${ }^{22}$ Liver transplantation is the only hope for the patient. $^{20}$ Indeed, many patients have undergone successful transplantation and survival to seven years has been reported. ${ }^{3}$ Recurrence of the tumour after liver transplantation has been described in a patient following contact with vinyl chloride. ${ }^{21}$ Although a liver transplantation programme is in its infancy at our institute, we have listed our patient for a transplant as a long term treatment strategy.
Given the slow growth of the tumour and relatively long survival, such patients may need the liver transplant at a later date during the course of the illness.

1 Forbes A, Portmann B, Johnson P, Williams R. Hepatic sarcomas in adults: a review of 25 cases. Gut 1987;14:501-3. 2 Weiss SW, Enzinger FM. Epithelioid hemangioendothelioma: a vascular tumour often mistaken for a carcinoma. Cancer 1982;50:970-81.

3 Ishak KG, Gesterhenn IA, Goodman MZD, Robin C Stromeyer FW. Epithelioid hemangioendothelioma of the liver: a clinicopathologic and follow up study of 32 cases. Hum Pathol 1984;15:839-52.

4 Radin BP, Craig JR, Colletti PM, Ralls PW, Halls JM Hepatic epithelioid hemangioendothelioma. Radiology Hepatic epithelioi

5 Furui S, Itai Y, Ohtomo K, Yamauchi T, Takenaka E, Ito M, et al. Hepatic epithelioid hemangioendothelioma: report of five cases. Radiology 1989;171:63-8.

6 Fedeli G, Certo M, Cannizzaro O, Forti G, Gimbo G Abagnale R, et al. Epithelioid hemangioendothelioma of the liver: report of two cases. Ital $\mathcal{f}$ Gastroenterol 1991;23:261-3.

7 Terg R, Bruguera M, Campo E, Hojman R, Levi D, Podesta A. Epithelioid hemangioendothelioma of the liver: report of two cases. Liver 1988;8:105-10.

8 Clements D, Hubscher S, West R, Elias E, McMaster P. Epithelioid hemangioendothelioma: a case report. $₹$ Hepatol 1986;2:441-9.

9 Weiss SW, Ishak KG, Dail DH, Sweet DE, Enzinger FM. Epithelioid hemangioendothelioma and related lesions. Semin Diagn Pathol 1986;3:259-67.

10 Lauffer JM, Zimmermann A, Krahenbuhl L, Triller J, Baer H. Epithelioid hemangioendothelioma of the liver: a rare hepatic tumour. Cancer 1996;78:2318-27.

11 Dean PJ, Haggitt RC, O'Hara CJ. Malignant epithelioid hemangioendothelioma of the liver in young women: relationship to oral contraceptive use. Am F Surg Pathol 1985;10:695-704

12 Miller WJ, Dood III GD, Federle MP, Baron RL Epithelioid hemangioendothelioma of the liver: imaging findings and pathological correlation. Am $¥$ Roentgenol 1992;159:53-7.

13 Skin MS, Carpenter JT, Ho KJ. Epithelioid hemangioendothelioma: CT manifestations and possible linkage to vinyl chloride exposure. $\mathcal{F}$ Comput Assist Tomogr 1991;15: 505-7.

14 Van Beers B, Roche A, Mathieu D, Delas M, Otte JB Lalonde L, et al. Epithelioid hemangioendothelioma: MR and CT findings. 7 Comput Assist Tomogr 1992;16:420-4.

15 Lee KS, Rosleigh MA, Fernandes VB, Morris JG. Scintigraphic features of malignant epithelioid hemangioendothelioma. Clin Nucl Med 1989;14:501-3.

16 Dietze O, Davies SE, Williams R, Portmann B. Malignant epithelioid hemangioendothelioma of the liver: a clinicopathological and histochemical study of 12 cases. Histopapathology 1990;17:237-42.

17 Arnold G, Klein PJ, Fischer R. Epithelioid hemangioendothelioma: report of a case with immunohistochemical and ultrastructural demonstration of its vascular nature Virchows Arch (A) 1986;408:435-43.

18 Traweek SJ, Kandelaft PL, Mehta P, Battifora H. The human hematopoietic progenitor cell antigen (CD34) in vascular neoplasia. Am f Clin Pathol 1991;96:25-31.

19 Weibel ER, Palade GE. New cytoplasmic components in arterial endothelium. $\mathcal{F}$ Cell Biol 1964;23:101-12.

20 Scoazec JY, Lamy P, Degott C, Reyness M, Feldman G, Bismuth $\mathrm{H}$, et al. Epithelioid hemangio-endothelioma of the liver: diagnostic features and role of liver transplantation. Gastroenterology 1988;94:1447-53.

21 Gelin M, Van de Stadt J, Rickaert F, De-Perz C, Levarlet H, Adler $M$, et al. Epithelioid hemangioendothelioma of the liver following contact with vinyl chloride. Recurrence after orthotopic liver transplantation. $f$ Hepatol 1989;8:99-106.

22 Holley MP, Cuschieri A. Epithelioid hemangioendothelioma of the liver: objective response to hepatic intra arterial 5-FU. Eur f Surg Oncol 1989;15:73-8.

23 Marino IR, Todos S, Tzakis AG, Klintmalm G, Kelleher M Iwatsuki S, et al. Treatment of hepatic epithelioid hemangioendothelioma with liver transplantation. Cancer 1988;62:2079-84. 